\title{
A Construção de Redes Públicas na Gestão Local: Algumas Tendências Recentes
}

\author{
Suzana Moura
}

\section{RESUMO}

O trabalho discute o significado e caraterísticas das redes públicas constituídas em processos de elaboração e definição de planos/projetos estratégicos, que buscam integrar o Governo Local e organizações da sociedade civil. Parte-se de uma leitura de duas tendências que aparecem como impulsionadoras de inovação na gestão local na atualidade, nas quais se situam os processos analisados: o que se denomina de empreendedorismo competitivo e de ativismo democrático. Tais categorias de análise são elaboradas a partir de contribuições de autores que têm refletido sobre as mudanças ocorridas na gestão de cidades na Europa, nos Estados Unidos e na América Latina, em particular, no Brasil. Agregam-se ao estudo as abordagens recentes sobre redes. São considerados dois casos para a análise dessas novas tendências: a experiência do Planejamento Estratégico de Barcelona, Espanha, que se desenvolve desde 1988; e a do projeto Cidade Constituinte de Porto Alegre, RS, implementado a partir de 1993.

Palavras-chaves: redes; desenvolvimento local; administração municipal; inovação.

\begin{abstract}
The work discusses the meaning and characteristics of public networks established in process of elaboration and strategic plans/projects definition, that aim integrate local administration and civil society organizations. It starts from the interpretation of two tendencies that appear to urge innovation in current local administration, in which analyzed process can be found: competitive entrepreneurialism and democratic activism. These categories of analysis are developed from the author's contribution that have given back an image on changes occurred in cities administration in Europe, USA and Latin America, specially Brazil. The recent issues of the networks are also associated to the studies done. Two cases to analyze these new tendencies are considered: Strategic Planning Experience of Barcelona (Spain), which has been developed since 1988; and Cidade Constituinte Project of Porto Alegre (Brazil), established since 1993.
\end{abstract}

Key words: networks; local development; local government; innovation. 


\section{INTRODUÇÃO}

O olhar o que se está produzindo de novo nas formas de gestão pública local na atualidade permite evidenciar duas tendências inovadoras. Uma que se afirma a partir dos anos 80 , sendo aqui denominada de empreendedorismo competitivo. E outra, já presente nos anos 70 , que se pode denominar de ativismo democrático ${ }^{(1)}$.

A primeira indica um movimento de redefinição do papel e atuação dos Governos Locais, com ênfase dada ao desenvolvimento de vantagens comparativas e à busca de maior eficiência da gestão urbana, visando à integração competitiva no mercado global. Nessa perspectiva destacam-se outros elementos característicos que aparecem como inovação: o Governo assume um papel de catalisador/ articulador de forças; privilegia-se a construção de espaços e mecanismos de cooperação privada e pública, assim como a formação de consensos em torno de projetos estratégicos; ganha relevância a utilização de práticas de gerenciamento empresarial na gestão local e do marketing urbano. Tal definição agrega contribuições de vários autores, cujas referências são processos que vêm ocorrendo em cidades americanas e européias a partir da década de 80. Dentre estes, ressaltamse: Harvey (1989), quando discute o novo "empreendedorismo urbano"; Borja (1994), quando trata do "protagonismo citadino"; e Osborne e Gaebler (1993), na abordagem do "governo empreendedor"(2).

Essa tendência aparece como resposta às crises e reestruturações que têm ocorrido no campo do Estado e da economia, a partir dos anos 70, quando se aprofunda a globalização dos fluxos financeiros e da produção e um incremento da competitividade interurbana. A referência a esses fatores macroestruturais, no entanto, não prescinde de considerarem-se as particularidades que pode assumir cada país e cidade. Le Galès (1995), por exemplo, chama a atenção para as diferenças entre o fenômeno nos Estados Unidos e na França, Grã-Betanha e Itália, tendo em vista que na Europa o Estado Central cumpriu, historicamente, um papel mais destacado. $\mathrm{O}$ estudo aqui apresentado segue essa linha.

Só mais recentemente, essa questão passa a ser visualizada e analisada na América Latina. Borja (1994) observa que os processos de descentralização e democratização ocorridos nos anos 80 , embora tenham levado à revalorização dos Governos Locais, não implicaram, de imediato, o avanço em relação ao protagonismo. Isso, ainda segundo o autor, passa a acontecer nos anos 90, através de iniciativas de implementação de planos estratégicos, como ocorrido no Rio de Janeiro (RJ), Bogotá (Colômbia) e Córdoba (Espanha) ${ }^{(3)}$. No Brasil encon- 
tram-se alguns estudos que, a partir das referências de Harvey (1989), analisam determinadas experiências locais, enquanto expressões do empreendedorismo urbano, os casos de Curitiba, PR (Pinhaez et al., 1993; Silva et al., 1993) e do Consórcio Intermunicipal do ABC paulista, iniciado em 1991 (Pacheco, 1993).

Enquanto essa última tendência vem sendo pouco observada, o ativismo democrático adquiriu importante visibilidade no Brasil em matéria de estudos. Esse termo indica um conjunto de idéias e práticas de gestão local, difundidas por governos de esquerda e progressistas, que enfatiza o aspecto do alargamento da democracia, ou radicalização, e da cidadania, em termos políticos e econômicos. Dentro disso distinguem-se como elementos demarcadores: a busca de construção de espaços de participação popular na gestão local, redefinidos, mais recentemente, enquanto novas esferas públicas de exercício da cidadania ativa e de controle sobre o Estado; o direcionamento para as demandas sociais, através da inversão de prioridades das políticas municipais; a democratização das informações e do acesso aos bens e serviços públicos; e a perspectiva assumida de construção de nova cultura política. Dentre os autores que analisam essa tendência citam-se: Pacheco (1993), Daniel (1990, 1994), Moura (1993, 1994), Kowarick e Singer (1993), Cacia-Bava (1994) e Leal (1994).

Nas duas tendências assinaladas, um dos aspectos que aparece como inovação diz respeito às formas como interagem o Governo e a sociedade civil, tendo em vista a cooperação pública- privada e/ou o alargamento da democracia e da cidadania, entre outros objetivos. Os arranjos interorganizacionais daí emergentes podem ser tomados enquanto Rede, à medida que apresentem alguns dos traços característicos do que vem sendo identificado como as novas redes.

A abordagem de redes, como expressão dos novos arranjos interorganizacionais que emergem na atualidade ${ }^{(4)}$, indica o incremento dos processos de interdependência entre atores e organizações e, particularmente, entre agentes públicos e privados. Ao mesmo tempo, identifica-se nessa emergência certo esgotamento da capacidade de integração e de coesão social das instituições representativas tradicionais e da eficácia das organizações burocráticas e do modelo de planejamento global e centralizado. Mesmo com as diferenças, é possível identificar pontos comuns nas diversas definições sobre essas redes. Expressam um tipo de articulação que envolve uma pluralidade de atores, sejam eles da mesma ou de distintas esferas de Governo, empresas de porte e atividades diversas, ONGs, organizações populares, de categorias profissionais e/ou de outra natureza. Essa articulação é menos hierárquica e estruturada, tendo em vista problemas/projetos delimitados, com base em relações mais ou menos formais e regulares. Destacam-se, ainda, as idéias de cooperação: mobilização de recursos, de solidariedade, de confiança; em se tratando do campo da ação pública, distinguem-se outros sentidos: o processamento 
de conflitos e divergências, a negociação e a democratização dos processos decisórios (Loiola e Moura, 1996). São exemplos as redes sistêmicas (Alter e Hage, 1993), e as redes políticas, segundo as definições de Miller (1994) e Lechner (1996).

Ao se propor identificar as características dessas redes recorre-se a outro tipo de abordagem, ou seja, rede enquanto instrumento de análise ${ }^{(5)}$. Nessa perspectiva, encontram-se estudos que avançaram no sentido de agregar variáveis, as quais envolvem aspectos relativos aos atores, à natureza das relações e às funções da rede, entre outros (Van Warden, 1992). A partir daí e tendo em vista o presente objeto de estudo, chegou-se a uma definição das seguintes variáveis para orientar a investigação: abrangência da rede, que indica a pluralidade dos atores envolvidos; grau de centralidade, ou seja, a incidência do Governo no processo e a participação relativa das organizações/atores da sociedade civil; funções, remete aos papéis desempenhados pela rede; a natureza dos vínculos, a presença de relações de cooperação, os conflitos, a negociação e troca; e publicidade, que indica o grau de visibilidade pública da rede.

A combinação dessas duas abordagens coloca-se como perspectiva interessante para o tratamento da problemática aqui exposta, ao se agregar à análise das características formais das redes a discussão do significado dos arranjos produzidos em contextos de renovação da gestão local, bem como do que representam de novo em face dos padrões tradicionais e correntes de intermediação de interesses.

\section{Os Casos em Análise}

A partir do exposto, destacam-se os dois casos que foram considerados paradigmáticos em termos das tendências assinaladas: o Planejamento Estratégico de Barcelona, Espanha (PEC) ${ }^{(6)}$ e o Cidade Constituinte de Porto Alegre, RS (CC).

Ambos surgem como tentativas de renovação da gestão local no sentido de projetar o desenvolvimento da cidade num horizonte de futuro, adotando um caminho distinto dos esquemas de planejamento de longo prazo, restritos ao âmbito técnico, bem como da administração setorial de serviços articulados em torno do orçamento anual. Por um lado, procurou-se constituir redes públicas e plurais, como mecanismo básico do processo de planejamento. Por outro, buscou-se integrar à agenda do debate público temas que vão além das demandas localizadas e imediatas, seja de um setor seja de partes do território, traduzindo-se em termos de diretrizes e projetos estratégicos para a cidade. As diferenciações ficam por conta do direcionamento dado a cada processo, entre outros fatores. 


\section{O PEC em Barcelona}

A experiência do PEC em Barcelona teve início em 1988, por iniciativa do Governo Local. Este encontra-se, desde as primeiras eleições democráticas de 1979, sob a direção do Partido Socialista da Catalunha e, particularmente, com o mesmo prefeito - Pasqual Maragall - desde 1982. Conjugam-se, nesse momento, dois processos que aparecem como motivadores da iniciativa. De um lado, a preparação dos Jogos Olímpicos, que se realizaria em 1992, e, de outro, a construção do Mercado Único Europeu.

A adoção do instrumental do planejamento estratégico, com um tipo de abordagem que enfatiza a cooperação entre agentes públicos e privados, entre Governo e sociedade $\operatorname{civil}^{(7)}$, vem responder às motivações iniciais, sejam elas de ordem econômica ou política ${ }^{(8)}$. Nos dois casos, ganha relevância a postura de diálogo e de busca da participação, tanto que se coloca a idéia de construção de um Plan de la Ciudad e não de um Plan del Ayuntamiento.

Nessa perspectiva é que se conjugou uma técnica específica de análise e projeção, com processos políticos de consulta e negociação, envolvendo diversos atores locais. Desde a sua formatação, passando pelo processo de elaboração e implementação do plano, considerou-se essencial a busca do consenso e de compromissos entre os agentes públicos e privados. Com base nisso constituiu-se um conjunto de espaços públicos - o Comitê Executivo, o Conselho Geral, as Comissões Técnicas e os Grupos de Impulso - que conformam a estrutura organizativa $\mathrm{PEC}^{(9)}$. Agrega-se, ainda, o instrumental do marketing, tendo em vista a mobilização interna e a atração de investimentos, dentro do horizonte de futuro e dos projetos delineados.

Desse modo, a proposta para a elaboração do primeiro plano foi firmada em maio de 1988 e a sua aprovação deu-se em março de 1990, ambas envolvendo organizações da sociedade civil. Após quatro anos, em que se implementou parte dos projetos definidos, foi aprovado o II Plan Estratégico Económico y Social, em novembro de 1994, mantendo-se em atividade até o momento de realização da pesquisa $^{(10)}$.

A partir da análise do conteúdo dos dois planos, assim como dos objetivos e dos procedimentos adotados, apontam-se alguns aspectos que evidenciam traços do empreendedorismo competitivo nessa experiência.

Destaca-se, inicialmente, a ênfase dada à questão da economia local e, especificamente, ao desenvolvimento de vantagens comparativas para um melhor posicionamento de Barcelona no mercado mundial, ou no mercado de cidades, como situam Martorell e Hernandez (1993). Este é um aspecto que está nas ori- 
gens do PEC, traduzindo-se no objetivo geral, nos temas e linhas estratégicas definidas nos dois planos ${ }^{(11)}$.

A referência ao processo de globalização e ao papel que as cidades podem cumprir, em matéria de desenvolvimento econômico, aparece com mais profundidade na análise do entorno no II Plano. Aí discute-se o aprofundamento da competitividade interurbana, sendo afirmado que, nesse contexto, poucas cidades ganham, adquirindo funções de comando na organização da economia mundial, e outras perdem ou, ainda, podem ficar em situação intermediária. Adota-se esta última situação para o caso de Barcelona, assumindo-se, então, a perspectiva de una ciudad internacional importante.

A ênfase nessa perspectiva de desenvolvimento local traduziu-se, também, na escolha inicial dos atores locais, os mais representativos, que integrariam o processo de concertação pública: as associações empresariais e instituições econômicas, públicas e privadas. A incorporação posterior das centrais sindicais veio responder a uma motivação política e agregou àquela orientação a problemática das desigualdades sociais. Esta aparece no objetivo do primeiro plano em termos de equilíbrio social e, no segundo, de integração social, traduzindo-se em medidas voltadas para os segmentos excluídos ou pouco incluídos pelo progresso econômico, dentre os quais os jovens, os idosos e os imigrantes.

Além da ênfase no desenvolvimento de vantagens competitivas, evidenciam-se outros aspectos do PEC que permitem analisá-lo como expressão do empreendedorismo.

O Governo Local assume papel de articulador de forças sociais e procura aparecer como mais um ator no processo. É nessa perspectiva que, desde o início, procurou comprometer outros atores locais para a construção de um plan de la ciudad. No entanto, conforme se verá adiante, este adquire maior relevância na prática, particularmente no financiamento do processo de planejamento.

Práticas de gestão empresarial tornam-se referência importante no processo, desde a adoção do instrumental do planejamento estratégico, até a utilização, no segundo plano, das noções de Qualidade Total visando a maior eficiência da cidade e do próprio plano.

A promoção da cidade, através de imagem forte e positiva, a metrópole empreendedora, associa-se com a do PEC, tanto interna como externamente. Ao lado do trabalho de publicidade e marketing do modelo ${ }^{(12)}$, que teve como um dos resultados a sua difusão na Europa e América Latina, os dois planos incorporaram medidas de promoção da cidade em termos turísticos e visando à atração de investimentos externos. 
Coloca-se como fundamental a cooperação público-privada e a formação de consensos, ao longo de todo o processo de formulação e implementação dos projetos estratégicos. Esses seriam elementos para assegurar a eficiência e garantir o êxito do PEC.

A partir desses aspectos evidencia-se que o desenvolvimento de estratégias competitivas se associa claramente, nessa experiência, ao esforço de articulação de forças por parte do Governo Local, o que, por sua vez, remete também a motivações de ordem política. Tal articulação materializa-se em um conjunto de espaços públicos que podem ser tomados como rede. Ao se analisar tais espaços, utilizando-se as variáveis apontadas na introdução ${ }^{(13)}$, evidenciam-se traços do empreendedorismo competitivo, assim como do que se definiu como novas redes. Distinguem-se, assim, os elementos característicos a seguir.

Trata-se de uma rede plural, em termos do leque de forças sociais mobilizadas, estando mais representado o segmento empresarial, entre outros mais diretamente vinculados à área econômica. Isso por conta do que é o propósito central do PEC, da direção dada ao mesmo desde o seu início.

Sua função básica é a formulação e implementação de projetos estratégicos, tendo por base o compromisso e o consenso dos atores integrantes. Mas esta função desdobra-se em outras, em face do caráter não executivo do PEC, da pluralidade da rede e da diferenciação das suas instâncias organizativas. Por isso constitui-se também como um espaço: para o exercício do lobby, visando à mobilização de recursos externos à rede; de pressão social, para que propostas minoritárias sejam, de fato, integradas; de articulação e (re)conhecimento de visões e interesses distintos; de informação e legitimação do processo de planejamento e dos projetos considerados estratégicos.

No tocante à natureza das relações entre os atores, observa-se importante dose de cooperação, com vistas ao processo de elaboração e implementação do plano. Isto decorre de motivos diversos, dentre os quais o trabalho inicial de comprometimento das organizações consideradas relevantes, o estabelecimento do consenso como regra básica e a presença de certa cultura de pactuação e diálogo. Mas perpassam na rede tensões e conflitos, que evidenciam a existência de blocos de interesses distintos e, ao mesmo tempo, não impedem a formação de alianças pontuais.

No processo, o Governo Local detém papel importante na iniciativa, no financiamento e na responsabilidade política, à medida que o próprio prefeito é o presidente do CG. No entanto parece situar-se como mais um ator na rede, haja vista que a intenção de fazer do PEC um espaço de compromisso e co-responsabilização, tem seu rebatimento na prática. Além disso, importa considerar o papel destacado 
da coordenação técnica que é constituída por profissionais de fora dos quadros da prefeitura.

Por fim, verificou-se que a publicidade da rede, a sua visibilidade pública, é um fato que se associa não só aos objetivos de atrair participantes e dar legitimidade ao $\mathrm{PEC}$, como também à promoção deste e da própria cidade. A eficácia deste trabalho no exterior pode ser medida pela ampla difusão do modelo na Europa e na América Latina ${ }^{(14)}$.

Tomando-se os elementos apontados, é possível distinguir semelhanças e diferenças perante as abordagens sobre as novas redes, bem como a experiência do CC. Esse aspecto será desenvolvido adiante, após a exposição desta última.

\section{O CC em Porto Alegre}

O Cidade Constituinte surgiu em 1993, no primeiro ano do segundo Governo da Frente Popular - FP ${ }^{(15)}$. Nas suas origens encontra-se forte motivação política, dar resposta às principais críticas da oposição na campanha eleitoral ${ }^{(16)}$. O Governo anterior foi criticado por investir apenas nas pequenas obras na periferia da cidade e na manutenção dos serviços básicos, sem atuação voltada para grandes projetos de desenvolvimento urbano, o que aparecia como o não pensar grande. Por parte da FP, a experiência mais difundida como inovadora, democrática e com respaldo popular foi a do Orçamento Participativo (OP), iniciada em 89.

Buscou-se, então, montar um projeto de "mobilização" que pudesse ser contraposto "à concepção tecnocrática e elitista do PMDB e dos partidos tradicionais de pensar as grandes questões da cidade"(17). Nesse sentido, a resposta política construída com o CC coloca-se numa perspectiva de ampliação da experiência anterior, em especial do OP, em dois níveis. Por um lado, busca-se ampliar a agenda do debate público para além do horizonte de um ano e das questões que são tratadas no orçamento anual. Isso com a idéia de discussão de diretrizes de desenvolvimento local, num horizonte de futuro. Por outro, pretende-se envolver um leque mais amplo de atores sociais nos processos participativos, em direção aos setores médios e ao empresariado. Estes tinham e têm pouca presença no OP.

Desse modo, desenvolveu-se um processo público de discussão, envolvendo o Governo, organizações públicas e da sociedade civil, a partir de um conjunto de instâncias: Coordenação Geral, Grupos de Trabalho e Congresso da Cidade ${ }^{(18)}$. Após o I Congresso em dezembro de 1993, que definiu o que seriam as diretrizes e projetos de desenvolvimento ${ }^{(19)}$, o processo caminhou no sentido da revisão do plano diretor, etapa que foi concluída em meados de $96^{(20)}$.

Tomando-se os elementos básicos do discurso e da prática, pode-se analisar o 
CC como uma expressão do ativismo democrático, visto enquanto traço caracterizador do Governo da Frente Popular de Porto Alegre.

As idéias básicas presentes no projeto inicial remetem a alguns dos termos do ideário que informa essa tendência. Os objetivos de mobilizar e qualificar a cidadania, de construção de um planejamento socialmente construído a partir de uma esfera pública não estatal, têm que ver com a perspectiva de democratização radical do Estado e de criar uma nova cultura política. Certamente tal perspectiva associa-se, neste contexto, a outros objetivos que estiveram na base da motivação do Governo para empreender o CC. Por um lado, tecer uma resposta às críticas da oposição e, por outro, afirmar um projeto político-partidário como alternativa de governo.

O CC é, mais precisamente, uma expressão desse ideário em bases renovadas, uma tendência observada nos anos 90 . Isto é, dirige-se para o conjunto da sociedade, aos próprios agentes econômicos, e com uma agenda que vai além da inversão de prioridades, a qual visa ao atendimento de demandas populares mais imediatas e localizadas. Tal aspecto pode ser evidenciado tanto nos objetivos do projeto - de ampliação do leque de atores a serem mobilizados e de discussão pública de um projeto de futuro e globalizante da cidade - como nos procedimentos adotados - os eixos temáticos, o chamamento à organizações empresariais, de setores médios e populares para integrarem a CG e os GTs, a realização dos eventos mobilizadores com discussão de temas estratégicos ${ }^{(21)}$.

Nessa renovação, ao mesmo tempo que se reproduzem idéias que informam aquele ideário, perpassam outras, que se encontram próximas ao empreendedorismo competitivo, embora com nuanças diferenciadas, por conta da hegemonia de um projeto político que enfatiza a questão da democratização radical do Estado e da sociedade.

A análise dos espaços públicos de participação constituídos nessa experiência, seguindo a mesma sistemática adotada no outro caso, permite destacar traços que os distinguem e aproximam da rede do PEC.

Trata-se de uma rede plural, em termos dos segmentos sociais envolvidos: empresarial, setores médios e populares. Tomando-se o conjunto das organizações participantes, verifica-se um nível de participação mais restrita dos primeiros.

O Governo assume uma centralidade importante, tanto na iniciativa como na condução do processo, correspondendo ao modo como o projeto foi apresentado: um projeto que expressa a vontade política de desafiar, ampliar e qualificar a cidadania. Isso, contudo, não impediu a interferência dos atores participantes no encaminhamento do processo e nos processos decisórios. 
As funções desempenhadas são múltiplas, apresentando certas ambigüidades: o debate e disputa de idéias e interesses, tendo em vista a definição de diretrizes de desenvolvimento; a difusão de informações, visões e demandas; até a homologação de propostas formuladas por fora da rede.

O mesmo foi observado na análise da natureza das relações, evidenciando uma complexidade que impossibilita qualquer definição do que seria a tônica: confiança e desconfianças, superadas em alguns casos pela convivência e por alianças pontuais, para defesa de posições convergentes; a cooperação com o andamento do processo, expressa em alguns momentos, foi perpassada em outros por conflitos e pressões, por dentro e por fora da rede; formação de vínculos mais orgânicos entre atores que compartilham valores comuns.

A rede adquiriu visibilidade pública, sendo o trabalho de publicidade voltado basicamente para a mobilização interna.

Partiu-se dos aspectos levantados para a análise das semelhanças e distinções observadas nos dois casos estudados, em termos das redes públicas constituídas em cada experiência. Com isso desenvolveram-se um pouco mais os elementos que as caracterizam, e discute-se o que trazem de novo.

\section{Diferenças e Convergências}

$\mathrm{Na}$ análise dos dois casos observa-se que a conformação das redes públicas se coloca como elemento central, com alguns pontos de convergência, mas essas assumem particularidades num e no outro caso, por conta das perspectivas adotadas. Verificou-se que as diferenciações mais significativas se situam no grau de centralidade e nas funções.

No PEC encontra-se uma rede próxima ao tipo multidirecional, cujo Governo Local aparece como mais um ator, e as organizações da sociedade civil apresentam importante grau de comprometimento e ingerência na condução do processo, particularmente os integrantes do CE. Enquanto isso, no CC afirma-se o papel de destaque do Governo Local, não só em termos da iniciativa e do financiamento, como também na condução de todo o processo. Isso requer um nível maior de envolvimento do conjunto da prefeitura e sinaliza uma rede do tipo unidirecional, sem que implique o fechamento da participação e ingerência dos atores sociais sobre o mesmo.

A idéia de construção de um plano estratégico da cidade, que está explícita no primeiro, e a própria criação de uma associação civil, Associação do Plano Estra- 
tégico Barcelona 2000, coaduna-se com a ótica do empreendedorismo de buscar a cooperação com o setor privado. Por outro lado, a perspectiva de democratização do Estado, num contexto em que o Governo Local busca afirmar um projeto político-partidário como referência nacional, parece impor uma ação mais decisiva deste.

Também por conta dessa diferenciação, as funções da rede no PEC vão além da etapa de formulação e definição de projetos estratégicos, os quais só em parte dependem do Governo Local para sua implementação, exigindo toda uma etapa de lobby visando à mobilização de recursos. Já no CC a marca é o debate e a disputa de idéias visando à definição de diretrizes de desenvolvimento, as quais norteariam as ações do Governo. De acordo com isso, a votação foi escolhida como regra para os processos decisórios, enquanto no primeiro se estabeleceu, de início, o consenso como norma básica, mais condizente com a ótica da cooperação e do compromisso entre agentes públicos e privados. Em ambos, a rede assume outros papéis: homologação, informação, consulta, aprendizado e qualificação dos atores participantes, sendo este último um objetivo explícito no projeto do CC.

Tanto no PEC como no CC observou-se que, dada a diversidade dos atores participantes e, portanto, dos interesses em jogo, a atitude cooperativa e a formação de alianças pontuais são perpassadas por conflitos e pela articulação de blocos entre os segmentos que compartilham valores comuns. $\mathrm{O}$ aspecto da disputa democrática de interesses, que se evidenciou mais no segundo, fez com que a questão dos conflitos emergisse de modo claro. Quanto á natureza desses conflitos, observou-se que no PEC se deu basicamente em torno do conteúdo do plano, ou seja, da tensão estabelecida entre a ênfase no desenvolvimento de vantagens competitivas e a ótica do equilíbrio social; no $\mathrm{CC}$ os conflitos emergiram principalmente em função da metodologia participativa: de um lado, a tensão entre uma abordagem técnica dos problemas e de projetos de desenvolvimento futuro da cidade, e a abordagem setorial dos interesses sociais em jogo; de outro, entre a direção do processo, com suas limitações e ambigüidades no grau de abertura democrática, e os atores que apresentavam demandas nesse sentido.

Nos dois casos constituíram-se redes públicas e plurais, considerando o leque de segmentos sociais envolvidos. No entanto no CC encontrou-se maior heterogeneidade, haja vista a inclusão de setores populares e ONGs, além das centrais sindicais, associações profissionais, empresariais e a universidade, mesmo no âmbito da CG - o caso dos representantes do OP, do Fórum da Reforma Urbana, entre outros. Ressalta-se, no caso do PEC, a presença significativa do segmento empresarial e, em contrapartida, uma participação minoritária de organizações vinculadas aos setores populares, o que remete ao próprio direcionamento 
dado ao processo. Situação inversa do ocorrido no primeiro, não em função dos objetivos postos, mas de dificuldades encontradas na operacionalização do projeto.

A abertura desses espaços para entrada de novos integrantes, ao longo do processo, é outro aspecto diferenciador do PEC, no qual se observa a permanência das mesmas instituições desde o seu início. As restrições à entrada de outros atores no $\mathrm{CE}$, deste último, remetem ao direcionamento dado, com a escolha, pela coordenação, das instituições representativas, entre associações empresariais, sindicais e técnico-profissionais. Já no CC as limitações, refletidas no descompasso entre o número de convidados e o de participantes, remetem a problemas de ordem metodológica, às imprecisões conceituais e às lacunas em termos de produção e difusão de informações, entre outros. Ao mesmo tempo, as desconfianças geradas por uma idéia nova que se quer implementar, bem como as decorrentes de um quadro onde o Governo Local não detém a hegemonia sobre o conjunto dos segmentos sociais, não foram enfrentadas por um trabalho inicial de convencimento e comprometimento com o CC, como o ocorrido em Barcelona.

A visibilidade pública da rede no PEC adquire uma importância que vai além da mobilização interna, associando-se com a promoção do próprio modelo de planejamento estratégico e da cidade no exterior, através de forte esquema de marketing. Já no CC a questão da publicidade associa-se basicamente ao aspecto da mobilização dos atores locais, sendo evidenciada, ainda, a essencialidade da produção e difusão de informações, como garantia para se alcançar um nível satisfatório de debate e disputa democrática. Considerando esses dois níveis de exigência, observou-se limitações de ordem técnica e política advindas do Governo Local, do qual dependia uma ação mais incisiva e qualificada nesse âmbito, já que se colocou como ator central no processo ${ }^{(22)}$.

A partir dessas considerações, que evidenciam as diferenciações e convergências entre as redes públicas do PEC e do CC, cabe refletir sobre o que apresentam de novo, em face do que vem sendo abordado como novas redes e diante dos padrões tradicionais de intermediação de interesses.

\section{Concluindo: Que Apontam de Novo?}

As redes constituídas nesses processos contêm elementos característicos de abordagens correntes sobre as novas redes, em especial no campo da ação pública; no entanto não se enquadram completamente em nenhum dos tipos apresentados.

O comum é envolverem-se atores plurais, públicos e privados, cujas relações 
são mais horizontais do que hierárquicas e pouco formalizadas, situadas numa zona intermediária entre o Estado e a sociedade civil, mas adquirindo caráter público. As funções e a natureza das relações podem ser variadas. Como se viu, a tônica da rede no PEC é a cooperação, enquanto no CC constituiu-se mais como arena de debate e disputa democrática de interesses. Ao mesmo tempo, expressaram-se outras funções, conforme visto anteriormente, evidenciando a complexidade das redes com esse tipo de amplitude.

Ressalta-se, ainda, que os dois casos não se dirigem para problemas e projetos setoriais, como apontam aquelas abordagens. São tentativas de construção de uma ação planejada, seja em termos de desenvolvimento econômico, ênfase do PEC, seja em termos de desenvolvimento mais global, caso do CC em seus propósitos e na primeira fase. A idéia, presente no primeiro, de que esse tipo de ação em rede vem no sentido de melhorar a eficiência da gestão local, coaduna-se mais com as análises que buscam explicar tal recurso como resposta à crise do Estado e ao conseqüente incremento da interdependência do público e privado. Já no segundo o mesmo é proposto, em vista do alargamento da democracia local, como parte de projeto político-partidário, o que vem agregar outros elementos ao debate; em contextos com tais características, não se trata de considerar o Governo como mais um ator na rede. Este assume papel destacado, ao se propor não apenas articular forças sociais, mas também apresentar e disputar projetos, e induzir novas práticas.

Pelas características apontadas, esse tipo de rede pública, ao mesmo tempo que se distingue dos padrões pluralistas e corporatistas de intermediação de interesses, contém alguns dos traços característicos destes. Por um lado, tanto em Barcelona como em Porto Alegre, evidencia-se a presença de uma sociedade civil dinâmica e diversa no seu tecido associativo. No entanto os atores sociais não se restringem ao exercício do lobby, de modo difuso, sobre os centros decisórios. Assumem, de fato, funções públicas, quando definem e/ou atuam na direção da implementação de políticas. Especificamente com relação ao PEC, o exercício do lobby ganha novos contornos, ao se constituir um grupo de interesses, que envolve agentes públicos e privados. Por outro lado, é a partir do Estado que se dá a iniciativa de articulação de organizações da sociedade civil. Porém nem os arranjos daí emergentes estão inscritos na sua institucionalidade, nem se restringem a um número limitado de organizações, as quais dependem de reconhecimento oficial, para deterem o monopólio da representação junto a suas categorias. Mesmo com as semelhanças observadas entre o espaço do Comitê Executivo no PEC e os esquemas tripartites de negociação, próprios do corporatismo concertacional ou macro, a rede constituída distancia-se desse modelo.

Seguindo-se nessa linha, verifica-se que essas experiências também se distanci- 
am dos padrões tradicionais de corporatismo do tipo setorial e do clientelismo, o caso do Brasil, e de corporatismo do tipo estatal, o caso da Espanha sob o regime franquista.

Olhando sob esse prisma essas experiências podem ser consideradas como inovadoras. O mesmo se pode dizer da rede do PEC, quando comparada com os canais de participação instituídos a partir de 1979 em Barcelona, com a transição democrática. Estes últimos, diferentemente do primeiro, constituíram-se e, em alguns casos funcionam, tendo em vista questões fundamentalmente políticas, entre as quais a democratização da gestão local. Em função disso e de outras condicionantes, apresentam características distintas, por exemplo: são regulamentados por lei e integram a estrutura da esfera local de Estado; assumem funções mais restritas - informação, consulta e proposição - dirigindo-se ao âmbito da política municipal, em termos setorial ou territorial; e possuem regras mais delimitadas de integração. Além destas, cabe destacar outra diferença: o aspecto da cooperação e do compromisso entre atores públicos e privados, tendo em vista a mobilização de recursos, no caso do PEC.

Em Porto Alegre, assim como em outros municípios brasileiros, constituiu-se nos anos 80, com a transição democrática, tipo semelhante de canais de participação, os denominados conselhos setoriais. Estes também se distinguem do CC, pelos mesmos motivos acima assinalados. No entanto, paralelamente, observa-se a ocorrência de espaços públicos, a exemplo do OP, que não são regulamentados em lei, assumindo um perfil mais próximo daquele - de debate e disputa de interesses - muito embora integrem na sua agenda questões mais restritas e possuam um caráter menos plural. São, justamente, os aspectos da pluralidade - a ampliação do leque de atores sociais em direção aos setores médios e empresariais - e do conteúdo da agenda pública - o deslocamento do debate para a questão das diretrizes e projetos estratégicos de desenvolvimento - que possibilitam uma leitura do CC como algo inovador na gestão pública local no Brasil.

Em síntese, o estudo realizado veio evidenciar a ocorrência de perspectivas diferenciadas de renovação da gestão local, as quais convergem na importância atribuída à conformação de redes públicas e plurais. Estas podem advir, por um lado, para incrementar a eficiência e as vantagens comparativas da cidade, num contexto de aprofundamento da competitividade interurbana e da globalização; por outro, em função de projetos políticos de ampliação da democracia e cidadania, respondem, em maior ou menor medida, às coordenadas postas por esse contexto. O que apontam de novo é que, ao mesmo tempo que podem sinalizar certo enfraquecimento do papel do Estado, ao deslocar responsabilidades para o âmbito da sociedade civil, vêm reafirmar a necessidade de articulação entre os dois campos. Este nível de articulação está longe da imagem liberal do mercado, no econômico ou no político. 


\section{Notas}

${ }^{1}$ Existem outras possibilidades além das duas apontadas, mas estas são as que adquiriram maior relevância, até então, dentro da literatura corrente que trata do tema. Biarez e Nivers (1994) e Villasante (1995), por exemplo, sinalizam os novos referentes da gestão urbana que advém dos movimentos ambientalistas. O segundo chama a atenção, ainda, para as contribuições dos movimentos feministas, particularmente em algumas cidades italianas.

${ }^{2}$ Além destes, outros autores, que foram tomados como referência, abordam o mesmo fenômeno, dentre os quais: Batley (1991), Biarez e Nivers (1994) e Le Galès (1994, 1995).

${ }^{3}$ Essas e outras cidades latino-americanas adotaram o modelo de planejamento estratégico de Barcelona, o qual teve no autor mencionado um dos colaboradores e difusores.

${ }^{4}$ Dentro dessa linha de abordagem encontra-se uma série de estudos, não só referentes a processos que se dão no campo da ação pública, como da produção e circulação de mercadorias e dos movimentos sociais. Dentre estes citam-se: Alter e Hage (1993), Miller (1994), Randolph (1993, 1994), Scherer-Warren (1994) e Lechner (1996).

${ }^{5}$ Estudos nessa linha apontam que o recurso à análise de rede contribui para superar as limitações das abordagens atomistas e estruturalistas, referidas às organizações e aos fenômenos sociais em geral (e. g.: Deroy-Pineau, 1991; De Bresson e Amesse, 1994; Mackenie, 1995).

${ }^{6}$ Adota-se a denominação Planejamento Estratégico de Cidade (PEC) para o modelo de Barcelona, por suas particularidades, relativamente a outros modelos de planejamento estratégico voltados para o setor público, a exemplo do Situacional (PES), desenvolvido por Carlos Matus. Vide McAllister e Moura (1996).

${ }^{7}$ A referência teórica adotada pelos mentores do PEC encontra-se em Bryson (1988), o qual resgata para o setor público elementos de abordagens voltadas para a área empresarial.

${ }^{8}$ Pretendia-se garantir a continuidade do processo de dinamização da economia que viria com a realização dos Jogos Olímpicos e adaptar a cidade às novas coordenadas postas pelo processo de unificação européia. Por outro lado, o Governo buscava ampliar a hegemonia política para evitar riscos de perda eleitoral, fenômeno que se apresentava para os socialistas em outras partes da Espanha (Marshal, 1994).

${ }^{9}$ Tal estrutura foi consolidada em 1993, enquanto uma associação civil sem fins lucrativos, a Associação do Plano Estratégico Barcelona 2000. Assim visava tornar mais operativa a gestão cotidiana do processo. Do CE participam 11 instituições, praticamente as mesmas desde o seu início, com acréscimo de uma em 1992. O CG é integrado por cerca de 190 participantes, entre organizações e participações individuais; no momento da sua instalação, em 1988, contava com 150. Os outro dois espaços funcionam em momentos específicos, nas fases de elaboração e implementação, respectivamente. 
${ }^{10}$ Pesquisa de campo realizada em fevereiro de 1996.

${ }^{11}$ Das três linhas estratégicas do primeiro plano, duas referem-se a essa perspectiva econômica: configurar Barcelona como uno de los centros direccionales de la macroregión e potenciación industrial y de servicios avanzados a la empresa. No segundo plano, são quatro entre as cinco definidas: facilitar los procesos de adaptación de los sectores económicos de la área de Barcelona en la economía mundial; garantir el despliegue de una moderna actividad económica de ámbito internacional; posicionamento del área de Barcelona en la economía internacional; e articulación económico-social del área de Barcelona.

${ }^{12}$ De acordo com Forn (1993), 50\% do orçamento do plano, entre 1988 e 1993, foi gasto com o trabalho de marketing. Tomando-se os orçamentos de 1995 e de 1996 (a previsão, neste último caso), este percentual cai para 27\% (Informe del Comité Executivo del Plan Estratégico, 1996).

${ }^{13}$ Para o desenvolvimento da análise utilizaram-se como fonte de dados as entrevistas realizadas, em fevereiro de 1996, com atores locais envolvidos, direta ou indiretamente, no PEC, bem como documentos oficiais, entre outros.

${ }^{14}$ Cabe registrar que no bojo desse processo foi criado o Centro Iberoamericano de Desenvolvimento Estratégico Urbano (CIDEU), em 1993, tendo como um dos objetivos a promoção de experiências locais de planejamento estratégico. Em 1996 o CIDEU passou a contar com 44 cidades associadas e, a partir do estudo realizado, verificou-se que na América Latina 14 cidades estavam implementando esse tipo de modelo, dentre as quais Rio de Janeiro, Bogotá, Montevidéu e Havana.

${ }^{15}$ Esta é uma coalizão formada, desde as eleições municipais de 1989, entre o Partido dos Trabalhadores (PT), o Partido Socialista Brasileiro (PSB) e o Partido Comunista Brasileiro (PCB). No início de 1990 o PCB, com a reformulação nacional, passa a denominar-se PPS (Partido Popular Socialista), mas no Rio Grande do Sul manteve-se um pequeno núcleo com a sigla originária. Esta coalizão foi alterada nas eleições de 1996 com a saída do PSB.

${ }^{16}$ Particularmente o PMDB que disputou o segundo turno com a FP, obtendo $33 \%$ dos votos válidos.

${ }^{17}$ Cidade constituinte - um projeto de mobilização para ampliar e qualificar a cidadania. Comissão Executiva, s/d. (mimeo).

${ }^{18}$ Para a CG foram convidadas 17 instituições, entre públicas, associações empresariais, profissionais, centrais sindicais, universidades e organizações vinculadas ao movimento popular. A participação efetiva foi mais reduzida e variada ao longo do processo, com novas inclusões. Os GTs eram espaços abertos e para o Congresso a sistemática adotada foi de inscrição de delegados das organizações participantes dessas duas instâncias.

${ }^{19}$ A discussão nos GTs desenvolveu-se a partir de quatro eixos temáticos: desenvolvimento econômico, reforma e desenvolvimento urbano, circulação e transportes e financiamento da cidade. Com base nessa discussão, na sistematização efetuada pela coordenação e em nove eixos estratégicos formulados a partir do Governo, definiram-se, no Congresso, as 
Diretrizes para Porto Alegre. O II Congresso aconteceu em dezembro de 1995 dentro do processo de discussão do plano diretor.

${ }^{20}$ Cabe esclarecer que após o primeiro ano, o projeto sofreu um esvaziamento político dentro do próprio Governo. Esse fator, aliado à imprecisões conceituais e metodológicas observadas no momento da sua formulação, entre outros, levou a mudanças nos rumos do projeto, que se restringiu, nessa última fase, a dar andamento a uma das diretrizes definidas.

${ }^{21}$ Paralelamente ao processo de discussão nos GTs e na CG, montou-se uma programação de conferências com intelectuais, prefeitos e profissionais, do Brasil e do exterior. Esta objetivou fornecer subsídios ao debate e mobibilizar a cidade, sendo mais intensa no primeiro ano.

${ }^{22}$ Isso não quer dizer que haja uma opção em Porto Alegre por não investir no marketing voltado para o âmbito externo, só que este tem ocorrido com base em outra experiência que aparece como de sucesso - o Orçamento Participativo. Sucesso este não alcançado pelo CC.

\section{ReferénCias BibliográficAs}

ALTER, G.;

HAGE, J.

Organizations working

together. London : Sage, 1993.

\section{BATLEY, R.}

Comparisons and lessons. In: BATLEY, R.; STOKER, G. (Orgs.). Local government in Europe : trends and developments. London : MacMillan, 1991. p. 210-229.

BIAREZ, S.;

NEVERS, J. (Orgs).

Gouvernement local et politiques urbaines. In: COLLOQUE INTERNATIONAL (1994: Grenoble). Actes... Grenoble : CERAT, 1994. p. 09-36.

\section{BORJA, J.}

Las ciudades y el planeamiento estratégico : una reflexión Europea e Latinoamericana. Barcelona, 1994. (mimeo).
BRYSON, J. M.

Strategic planning for public and nonprofit organizations. London : Jossey-Bass, 1988.

CACCIA-BAVA, S.

Trocando a riqueza de mãos : distribuição de renda e poder nas pequenas cidades. Revista Proposta, n. 54, p. 12-16, 1994.

DANIEL, C.

As administrações democráticas e populares em questão. Espaço e Debates, n. 30, p. 11-27, 1990.

Gestão local e participação da sociedade. Participação Popular nos Governos Locais, n. 14, p. 21-42, 1994.

DE BRESSON, C.;

AMESSE, F.

Networks of innovators : a review and introduction to the issue. Research Policy, n. 10, p. 363379, 1994. 
DEROY-PINEAU, F.

Reseaux sociaux et mobilisation de ressources. Revue Pour, n. 132, p. 119-130, 1991.

FORN, M.

El plan estratégico Barcelona 2000 : una reflexión general. Urbanismo, n. 19, p. 18-25, mayo 1993.

HARVEY, D.

From managerialism to entrepreneurialism : the transformation in urban governance in late capitalism. Geografiska Annaler, n. 71b, p. 03-17, 1989.

KOWARICK, L.;

SINGER, A.

A experiência do Partido dos Trabalhadores na prefeitura de São Paulo. Novos Estudos, n. 35, p. 195-216, mar. 1993.

\section{LEAL, S.}

Para além do estado : tendências, limites e alcance das novas formas de gestão urbana. Campinas, 1994. Tese (Doutorado) - Universidade de Campinas.

\section{LECHNER, N.}

Reforma do estado e condução política. Lua Nova, n. 37, p. 33-55, 1996.

\section{LE GALÈS, P.}

Du gouvernement des villes à la gouvernance urbaine. Revue Française de Science Politique, v. 45, n. 1 , p. 57-95, fèv. 1995 .

Villes en compétition? In: $\begin{array}{llllllll}C & O & L & L & O & Q & U & E\end{array}$ INTERNATIONAL (1994: Grenoble). Actes... Grenoble : CERAT, 1994. p. 443-461.
LOIOLA, E.;

MOURA, S.

Análise de redes : uma contribuição aos estudos organizacionais. In: FISHER, T. (Org.). Gestão contemporânea, cidades estratégicas e organizações locais. Rio de Janeiro : Fundação Getúlio Vargas, 1996. p. 53-68.

MACKENIE, G. A.

Tipology of organizational network designs. In:

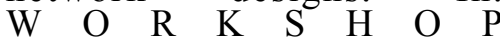
INTERNATIONAL NETWORK (1995: Jouy-en-Josas). Proceedings... Jouy-en-Josas : European Science Foundation Programme, 1995.

MARSHAL, T.

Barcelona - fast forward?

Oxford, 1994. (mimeo).

MARTORELL, F. S.; HERNÁNDEZ, J. C.

In: PRIMER SEMINARIO TÉCNICO DEL CENTRO IBEROAMERICANO DE DESSAROLLO ESTRATÉGICO URBANO (1993 : Barcelona). Anais... Barcelona : CIDEU, 1993.

MCALLISTER, M.; MOURA, S.

Cidade estratégica e gestão empreendedora : uma operacão de planejamento, pacto e marketing. Organização e Sociedade, v. 3 , n. 6, p. 07-30, 1996.

MILLER, H.

Post-progressive public administration : lessons from policy networks. Public Administration Review, v. 54, n. 4, p. 378-385, 1994. 
MOURA, S.

Inovações municipais em tempos de democratização e crise : novos cenários da gestão urbana. Análise e Dados, n. 1, p. 127-134, jun. 1993.

A questão público-privado : antigos e novos sentidos. In: XVIII ENCONTRO ANUAL DA ANPAD (1994 : Curitiba). Anais... Curitiba : ANPAD, 1994.

OSBORNE, D.;

GAEBLER, T.

Reinventing government : how the entrepeneurial spirit is transforming the public sector. New York : Plume Book, 1993.

PACHECO, R.

Iniciativa econômica local : a experiência do ABC. In: LODOVICI, E. S.; BERNAREGGI, G. M. Parceria público-privado : cooperaçao financeira e organizacional entre $o$ setor privado e administrações públicas locais. São Paulo : Summus, 1993. v. 2.

PINHANEZ et al.

Curitiba - uma estratégia de marketing. São Paulo, 1993. (mimeo).
RANDOLPH, R.

Redes estratégicas e de solidariedade. In: V ENCONTRO NACIONAL DA ANPUR (1993: Belo Horizonte). Anais... Belo Horizonte : ANPUR, 1993.

Novos agentes, novas fronteiras e novas espacialidades - umas reflexões sobre a sociedade brasileira contemporânea. In: WORKSHOP AVALIAČÃO DO PLANEJAMENTO URBANO E REGIONAL (1994 : Gramado). Anais... Gramado : ANPUR, 1994.

SCHERER-WARREN, I.

Metodologia de redes para o estudo das organizações. Salvador : VI Colóquio sobre Poder Local, 1994. cassete son.

SILVA, T. L. DA et al.

Governo local empreendedor em Curitiba : mito ou realidade? São Paulo, 1993. (mimeo).

VAN WARDEN, F.

Dimensions and kinds of policy networks. European Journal of Political Research, 1992.

VILLASSANTE, T.

Las democracias participativas : de la participación ciudadana a las alternativas de la sociedad. Madrid: Ediciones HOAC, 1995. 